\title{
降伏荷重を受けるピントラスの非弾性挙動について
}

\author{
正員西村昭*

\section{INELASTIC BEHAVIOR OF PIN-CONNECTED TRUSS UNDER YIELD LOADS}

Akira Nishimura, C.E. Member.

\section{Synopsis :}

To obtain some data on the critical state of truss bridge, its inelastic behavior in the plastic range in which any lower chord of the truss starts to flow is solved dynamically and simultaneously the effect of travelling velocity of moving load is presented by using the numerical example of the Warren type truss highway bridge of $70 \mathrm{~m}$ long and $4.5 \mathrm{~m}$ wide with curved chords, in this paper. In these performances, it should be taken into consideration that the tensile stress-strain curve of mild steel consists of the three ranges; elastic-, plastic flow-, and strain hardening-regions.

The deformation, when plastic flow occurred in any member, is calculated from the motion of the mechanism consisting of two structual parts each of which is assumed rigid body and are joined with each other by a frectionless hinge existing on the apex opposite to the yielded member. And, two concentrated loads acting on the panel points of the both ends of a lower chord member which will yield when the loads get to the same maximum value, are varied trapezoidally with time, in order to obtain the same effect as that of the moving load.

要 旨 構造用軟鋼よりなるトラスの極限状態についての資料を得るために, 単純橋トラスの下弦材降 伏の場合につき, 動力学的見地よりその非弾性挙動を明らかにしたものである。降伏部材とついては弾性 変形, 塑性流動及びヒズミ硬化の各領域を考虑し, 流動開始以後に和けるトラス挙動怯, 降伏部材に相対

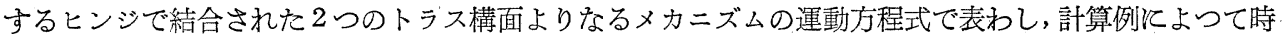
間的飞台形状の変動を示す集中荷重を受ける下路ワレントラスの中央下玹材降伏後の挙動, 及びそれに及 ぼす荷重速度の影響等を明らかとした。

\section{1. 緒言}

構造物設計の合理化飞当つては，作用荷重の適切な推定と共に 構造物の極限状態関する資料が必要である。 従来静定鋼構造物では軟鋼の理想塑性の仮定のもとに一部材，またハリの場合には一断面，の降伏によつて变形 は無限大となり，従つて構造物の耐荷力は尽きるとされてきた。これは構造物の使用上永久変形を残すことが許 されない場合には至極妥当である。しかし構造物作用する荷重は特殊な場合を除き一般注相当なチラバリを 有し，極言すれば設計荷重以上の荷重状態，あるいはある部材降伏を生ぜしめるような荷重状態はある確率の もとに必らず生起すると言いうる。構造物の公共性の増大につれてその設計荷重の増加めるいは許容応力の低下 を必要とするわけであるが，との場合でも上記の確率は０とはならないこのようと考光てくると，静定構造物 の極限状態として一部材あるいね一断面の降伏を採る場合でる，ある確率をるつて起りうる降伏を生ぜしめるよ うな荷重に対する安全性を保証するためには，その極限状態の理解は極めて重要な意義を有する。

構造用軟鋼の荷重・変形関係は，周知の通り弾性変形，塑性流動及びヒズミ硬化の各領域よりなるが，この第 三領域に入れば変形の増大に対する抵抗力ね増大することになる。ここではこのよろな抵抗増加も考虑して，ま， ず静定ピントラスの降伏荷重による降伏部材発生後の性状を明らかにした。

トラス下弦材応力の移動荷重による変動状態は，との影響線より明らかなように一般にほぼ台形状を示す。そ こで本研究では作用荷重としては移動荷重を用いる代りと，降伏部材端に作用する一対の集中荷重で置き換觉， その荷重値を時間的に台形状に変化せしぬた。气の他次の仮定を設けている。すなわち, 荷重速度の変化によつ て材料の変形は影響を受けないとした。この点と関しては移動荷重として普通の自動車荷重を対象とする場合は，

* 神戸大学助教授, 工学部土木教室 
その移動速度範囲内での荷重変化速度の差程 度では上記仮定は妥当であると考学る。また 動荷重飞付随する振動, 衝擊等の諸効果水一 応考觉ないことにした。

な招圧縮材の座屈による構造物の破猿る 起りうるが，この場合汇は座屈後の部材抵抗 力は乞れ以前に比して減少するのが常であ り，ここでは圧縮材の座屈による構造物変形 ほ取扱つていない。また対象構造物には活荷 重のチラバリの著しい道路橋を採つた。

\section{2. 基礎方程式の誘導 ${ }^{1}$}

静定ピントラスの下弦材降伏後の状態を図 示すれば一般飞 図一1（b）の通りである。

FG を破損部材とすると降伏後のトラスの変 形は塑性変形量に比して弾性変形量を無視す れぶ，ヒンジ Eで結合された 2 つ剛体の運 動変位として与兄られる。B及びCを破損部 材に相対するヒンジ $\mathrm{E} の$ 左右構面の重心とす ると，道路橋を対象とする場合はその死荷重 の大部分は床構造によつて占められることを 考慮すれば，その位置忙近似的に左右構面の 下弦材中央にあると考光られる。 $I_{1}, I_{2}$ をそ れぞれ B,C の回りの各構面の 2 次モーメン 卜， $m_{1}, m_{2}$ 及び $W_{1}, W_{2}$ をそれぞれ各構面の 質量及び重量とする。部材 FG の降伏部材応 力を $\mathrm{F}_{p}$, 時間 $t$ と和将る一対の外力をそれ

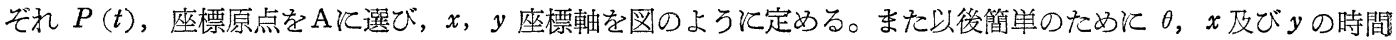
そよる 1 次及び 2 次微分係数をとれぞれ $\dot{\theta}, \ddot{\theta}$ 等で表わす。

左構面のみを取り出して点 $\mathrm{A}$ の回りのモーメントの釣合を考学ると（図一1 (c)),

$$
\left.\begin{array}{c}
I_{A} \ddot{\theta}_{1}=\frac{1}{2} W_{1} L_{1} \cos \theta_{1} F_{p}\left(L_{1}-L_{3 L}\right)\left(\sin \alpha \cos \theta_{1}+\cos \alpha \sin \theta_{1}\right)+P(t)\left(L_{1}-L_{3 L}\right) \cos \theta_{1} \\
-R_{E V}\left(h \sin \theta_{1}+L_{1} \cos \theta_{1}\right)+R_{E H}\left(h \cos \theta_{1}-L_{1} \sin \theta_{1}\right) \\
\text { ここに, } \quad \alpha=\tan ^{-1}\left(y_{G}-y_{F}\right) /\left(x_{G}-x_{F}\right)
\end{array}\right\}
$$

また図一1（b）飞秥いて点Aの回りのモーメントの釣合条件より，

$$
\begin{aligned}
R_{D V}= & \frac{1}{L_{1} \cos \theta_{1}+L_{2} \cos \theta_{2}+h\left(\sin \theta_{1}+\sin \theta_{2}\right)}\left[\left(W_{1}-m_{1} \ddot{y}_{B}\right) \frac{L_{1}}{2} \cos \theta_{1}-m_{1} \ddot{x}_{B} \frac{L_{1}}{2} \sin \theta_{1}\right. \\
& -\left(I_{1} \ddot{\theta}_{1}-I_{2} \ddot{\theta}_{2}\right)+\left(W_{2}-m_{2} \ddot{y}_{C}\right)\left\{L_{1} \cos \theta_{1}+\frac{L_{2}}{2} \cos \theta_{2}+h\left(\sin \theta_{1}+\sin \theta_{2}\right)\right\} \\
& -m_{2} \ddot{x}_{C} \frac{L_{2}}{2} \sin \theta_{2}+P(t)\left\{\left(L_{1}-L_{3 R}\right) \cos \theta_{1}+L_{1} \cos \theta_{1}+L_{2} \cos \theta_{2}\right. \\
& \left.\left.+h\left(\sin \theta_{1}+\sin \theta_{2}\right)-\left(L_{2}-L_{3 R}\right) \cos \theta_{2}\right\}\right]
\end{aligned}
$$

一方図-1（c）と同様に右構面飞ついての水平及び鉛直方向の力の釣合条件より，

$$
\begin{aligned}
& R_{E H}=m_{2} \ddot{x}_{C}-F_{p} \cos \alpha \\
& R_{E V}=R_{D V}-F_{p} \sin \alpha-P(t)-\left(W_{2}-m_{2} \ddot{y}_{C}\right)
\end{aligned}
$$

式（4）江式（2）を用いて

$$
\begin{aligned}
R_{E V}= & P(t) \frac{\left(L_{1}-L_{3 L}\right) \cos \theta_{1}-\left(L_{2}-L_{3 R}\right) \cos \theta_{2}}{\bar{L}}+\left(W_{1}-m_{1} \ddot{y}_{B}\right) \frac{\frac{1}{2} L_{1} \cos \theta_{1}}{\bar{L}}-F_{p} \sin \alpha \\
& -\frac{I_{1} \ddot{\theta}_{1}-I_{2} \ddot{\theta}_{2}}{\bar{L}}-\frac{1}{\bar{L}}\left\{\frac{1}{2}\left(L_{1} m_{1} \ddot{x}_{B} \sin \theta_{1}+L_{2} m_{2} \ddot{x}_{C} \sin \theta_{2}\right)-\left(m_{2} \ddot{y}_{C}-W_{2}\right) \frac{1}{2} L_{2} \cos \theta_{2}\right\}
\end{aligned}
$$


$\theta$ が小なる場合には式 (1)，(3) 及び (5) よりとれどれ，

$$
\begin{aligned}
I_{A} \ddot{\theta}_{1}= & \frac{1}{2} W_{1} L_{1}-F_{p}\left(L_{1}-L_{3} L\right)\left(\alpha+\theta_{1}\right)+P(t)\left(L_{1}-L_{3 L}\right)-R_{E V} L_{1}+R_{E H}\left(h-L_{1} \theta_{1}\right) \\
R_{E H}= & m_{2} \ddot{x}_{C}-F_{p} \\
R_{E V}= & P(t) \frac{L_{1}-L_{3 L}-L_{2}+L_{3 R}}{\bar{L}}+\left(W_{1}-m_{1} \ddot{y}_{B}\right) \frac{L_{1}}{2 \bar{L}}-F_{p} \alpha \\
& -\frac{\left(I_{1}-I_{2} \frac{L_{1}}{L_{2}}\right) \ddot{\theta}_{1}}{\bar{L}}-\frac{1}{2 \bar{L}}\left\{L_{1}\left(m_{1} \ddot{x}_{B}+m_{2} \ddot{x}_{C}\right) \theta_{1}-L_{2}\left(m_{2} \ddot{y}_{C}-W_{2}\right)\right\}
\end{aligned}
$$

が得られる。但しここに,

$$
\bar{L} \equiv L_{1} \cos \theta_{1}+L_{2} \cos \theta_{2}+h\left(\sin \theta_{1}+\sin \theta_{2}\right)
$$

$\theta$ が小なる場合は

$$
\begin{aligned}
\bar{L} & \fallingdotseq L_{1}+L_{2} \\
\theta_{2} & \fallingdotseq \theta_{1} L_{1} / L_{2} \\
\text { 一方, } \quad x_{B} & =\frac{L_{1}}{2} \cos \theta_{1}, \quad x_{C}=L_{1} \cos \theta_{1}+\frac{L_{2}}{2} \cos \theta_{2}+h\left(\sin \theta_{1}+\sin \theta_{2}\right), \\
y_{B} & =-\frac{L_{1}}{2} \sin \theta_{1}, \quad y_{C}=-\frac{L_{2}}{2} \sin \theta_{2}
\end{aligned}
$$

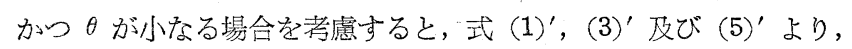

$$
\begin{aligned}
& \left\{\frac{1}{3} m_{1} L_{1}{ }^{2}+\frac{L_{1}}{L_{1}+L_{2}}\left(\frac{1}{6} m_{1} L_{1}{ }^{2}-\frac{1}{6} m_{2} L_{1} L_{2}\right)-m_{2} h^{2}\left(1+\frac{L_{1}}{L_{2}}\right)+m_{2} \frac{h\left(L_{1}{ }^{2}+2 L_{1} L_{2}\right)}{L_{2}} \theta_{1}\right\} \ddot{\theta}_{1} \\
& +\left\{m_{2} \theta_{1}\left(\frac{L_{1}{ }^{3}+L_{1}{ }^{4} / L_{2}}{2\left(L_{1}+L_{2}\right)}-L_{1}{ }^{2}-\frac{L_{1}{ }^{3}}{2 L_{2}}\right)+m_{2} h\left(L_{1}+\frac{L_{1}{ }^{2}}{2 L_{2}}\right)\right\} \dot{\theta}_{1}{ }^{2} \\
& =\frac{1}{2} W_{1} L_{1}\left(1-\frac{L_{1}}{L_{1}+L_{2}}\right)+\frac{1}{2} W_{2} L_{2} \frac{L_{1}}{L_{1}+L_{2}}-\frac{P(t)}{L_{1}+L_{2}}\left(L_{2} L_{3 L}+L_{1} L_{3 R}-2 L_{1} L_{2}\right) \\
& -F_{p}\left(h-L_{3 L} \theta_{1}\right)+F_{p} L_{3 L^{\alpha}}
\end{aligned}
$$

更に特別な場合として降伏部材に対して構造及び変形対称の場合には次のよろと簡単になる。

$$
\begin{aligned}
& \left\{\left(\frac{1}{3} m_{1} L_{1}{ }^{2}-2 m_{1} h^{2}\right)+3 m_{1} L_{1} h \theta_{1}\right\} \ddot{\theta}_{1}+\left(\frac{3}{2} m_{1} L_{1} h-m_{1} L_{1}{ }^{2} \theta_{1}\right) \dot{\theta}_{1}{ }^{2} \\
= & \frac{1}{2} W_{1} L_{1}+P(t)\left(L_{1}-L_{3 L}\right)-F_{p}\left(h-L_{3} \theta_{1}\right)
\end{aligned}
$$

式 (6) 及び式 $(6)^{\prime}$ が降伏部材が塑性流動を生ずる領域と怙けるトラスの運動方程式である。な特 $F_{p}$ ほヒズ 々硬化領域突入後は 4. そ述べるように $\theta$ の関数 $F(\theta)$ で置き換えられることになる。

\section{3. 降伏部材変形量亡構面回䎐角之の関係}

前述のようにトラスの変形は図一1 (b) のようとヒンジ E で結合されて回転する2つの剛体の運動状態を明ら かルすることによつてえられる。この場合の変形の幾何学的条件より，

$$
\left.\begin{array}{l}
\Delta r_{1}=-\left(\theta_{1}+\alpha\right) \\
\Delta r_{2}=-\left(\theta_{2}-\alpha\right)
\end{array}\right\}
$$

部材 $\mathrm{FG}$ の変形前の部材長を $l\left(=L_{3}+L_{3 R}\right)$ とすると,

$$
l=s_{1} \cos r_{1}+s_{2} \cos r_{2}
$$

$l$ の総変形量を $\Delta l$ とすると, $\theta$ が微小な場合は式 (7) を考慮して,

$$
\Delta l=-s_{1} \sin r_{1} \Delta \gamma_{1}-s_{2} \sin r_{2} \Delta r_{2}=-s_{1} \sin r_{r}\left(\Delta r_{1}+\Delta r_{2}\right)=h\left(\theta_{1}+\theta_{2}\right)
$$

となる。また対称変形の場合には，

$$
\Delta l=2 h \theta_{1}
$$

さて, 部材 FG の弾性変形 (変形量 $\Delta l_{e}$ ) 終了時飞抬ける左右構面回転量をそれぞれ $\theta_{1 e}, \theta_{2 e}$ とすると, 部材 FG の塑性変形量 $\Delta l_{p}$ ほ,

$$
\Delta l_{p}=\Delta l-\Delta l_{e}=h\left\{\left(\theta_{1}-\theta_{1 e}\right)+\left(\theta_{2}-\theta_{2 e}\right)\right\}
$$

式 (8), (8)' 及び (9) そよつて降伏部材変形量と構面回転量との関係を知ることが出来る。

\section{4. ヒズミ硬化領域における降伏部材力}

降伏部材 FG はトラス構面の回転量 $\theta$ の増加従つて塑性流動を終了し，ヒズミ硬化領域に突入することとな 
るが，ここではその場合の部材応力 $F(\theta)$ を求めて拉く。

まず軟鋼の荷重・伸び関係を図一2 のように仮定する。い ま部材力を $F(\theta)$, 部材断面積を $A$ ，ヤング係数を $E$ とする 々, 塑性流動完了時飞和ける変形量 $\Delta l_{e+p}$ 注,

但しここに

$$
\left.\Delta l_{e+p}=\Delta l_{e}+\Delta l_{p}=\frac{F_{p} l}{E A}(1+n)\right\}
$$

$$
n=\Delta l_{p} \mid \Delta l_{e}
$$

従つてヒズミ硬化領域突入後の部材総変形量 $\Delta l$ は, $E^{\prime}$ をヒズミ硬化領域に抒ける応力・ヒズミ比とすると，

$$
\Delta l=\frac{\left(F(\theta)-F_{p}\right) l}{A E^{\prime}}+\frac{F_{p} l}{A E}(1+n)
$$

図一2 軟鋼の荷重・伸び関係

Fig. 2 Force-deformation relation of mild steel

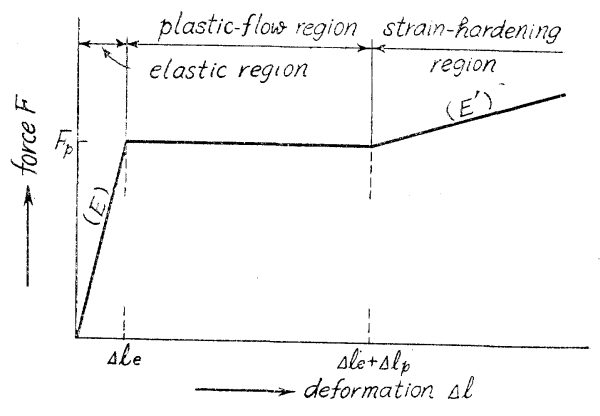

となる。ここで $E^{\prime}$ は実際には $\Delta l$ と 1 次関係にないが,ここでは簡単のために, 安全側であることも考虑して, 塑性流動完了点と最大引張強さ点を結ぶ割線の勾配を用いることにした。式 (8) を用いて $F(\theta)$ を求めると,

$$
F(\theta)=\frac{A E^{\prime}}{l}\left\{h\left(\theta_{1}+\theta_{2}\right)+\frac{F_{p} l}{A}\left(\frac{1}{E^{\prime}}-\frac{1+n}{E}\right)\right\}
$$

となる。また対称変形の場合には

$$
F(\theta)=\frac{A E^{\prime}}{l}\left\{2 h \theta_{1}+\frac{F_{p} l}{A}\left(\frac{1}{E^{\prime}}-\frac{1+n}{\varepsilon}\right)\right\}
$$

故に降伏部材がヒズミ硬化領域に大つて後は, 構面の運動方程式式 (6) めるいは (6)'の $F_{p}$ ほ式(11) あるいは (11)'で和き換えられなければならない。このときの適用境界の判定は式 (9) 及び (10) とよつて容易になされる。

\section{5. 長大スパン下路トラス橋についての数}

\section{值計算例}

以上誘導された基礎方程式を用いて 図一3

(a) 飞示す下路トラス道路橋の非弾性変形量 を計算してみる。

a. トラスに関する諸量 計算例に選んで トラスはスパン $70 \mathrm{~m}$, 有効幅員 $4.5 \mathrm{~m}$ の下 路曲弦ワレントラス橋である（図一-3(a)）。設 計注旧鋼道路橋設計示方書案（昭和 15 年） を用いて, 床及び組の設計とは, 第 1 種荷 重, 主構の設計々は第 2 種荷重を採用した。 材料は構造用軟鋼 SS- 41 , 死荷重の総計は各 主構について $2166 \mathrm{~kg} / \mathrm{m}$ である。

b. 使用材料江関する諸量 SS-41 の機械 的性質として次の值を用いた。すなわち， $E$ $=2.1 \times 10^{6} \mathrm{~kg} / \mathrm{cm}^{2} ; E^{\prime}=5.0 \times 10^{3} \mathrm{~kg} / \mathrm{cm}^{2}$; $\sigma_{p}=2700 \mathrm{~kg} / \mathrm{cm}^{2} ; \sigma_{B}=4000 \mathrm{~kg} / \mathrm{cm}^{2} ; n=$ 222) である。

c. 荷重 図一-3 と示したようと, 格点 $L_{4}, L_{6}$ Vとれぞれ同大の鉛直集中荷重 $P(t)$ が作用する対称変形の場合を考光ると, 下弦 材の部材応力气の他は表一1 と示す通りであ る。従つて $P(t)_{\max }=156695 \mathrm{~kg}$ そよつて $L_{4}-L_{6}$ 部材がまず降伏し, トラスはメカニ ズムとしての運動を開始することそなる。

部材 $L_{4}-L_{6}$ 飞注目寸ると, その部材灾力 の移動荷重による変動状況は, 影響線によつ て知られるようと台形状となる。とこでここ

\section{図一3 計算例トラス及び荷重}

Fig. 3 Truss bridge and variation of load acting on it

(a) skeleton of truss,

(b) loading pattern No. $1 \sim$ No. 5, and

(c) loading pattern No. 6

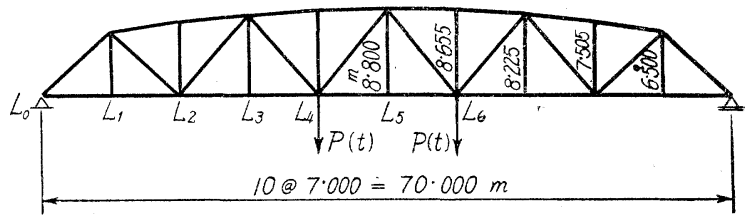

(a)

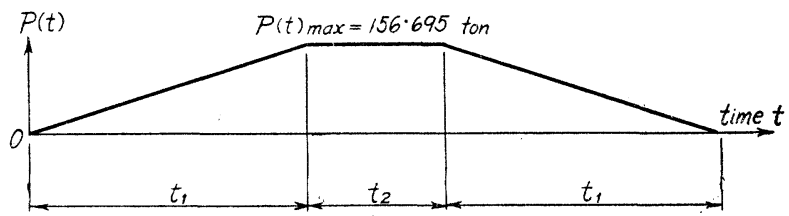

\begin{tabular}{|c|c|c|c|c|c|}
\hline 部 & 部材忘力 & $\begin{array}{l}\text { 総断面積 } \\
\left(\mathrm{cm}^{2}\right)\end{array}$ & $\begin{array}{c}\text { 死荷重応力 } \\
(\mathrm{kg})\end{array}$ & 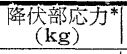 & $\begin{array}{l}\text { 降伏荷 重 }{ }^{*} \\
P(t)(\mathrm{kg})\end{array}$ \\
\hline$L_{0} L_{2}$ & $+1.077 P(t)$ & 111.48 & 65348 & 300996 & 218800 \\
\hline$L_{2} L_{4}$ & +2.553 & 201.48 & 129018 & 544000 & 162547 \\
\hline$L_{4} L_{6}$ & +3.182 & 238.28 & 144752 & 643356 & 156695 \\
\hline
\end{tabular}

(b)

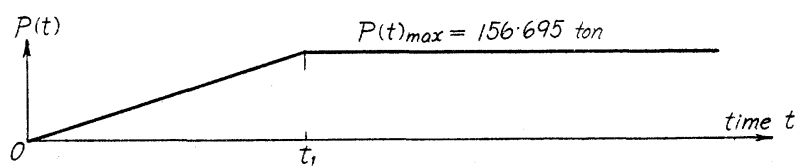

(c)

表一1

* 総断面積について計算 
では $P(t)$ の作用位置を不動とし, その絶対值の時閒的変動状況を図一-3(b) のように台形状に兄らび移動荷重 と同様の効果を生ぜしめた。

まず最初に $\mathrm{P}(t)_{\text {max }}=156695 \mathrm{~kg}$ の場合につき， $t_{1}$ 及び $t_{2}$ を時速 $15,25,35,45$ 及び $55 \mathrm{~km} / \mathrm{hr}$. で橋梁を通 過する移動荷重の各々の場合に対応せしめてそれぞれ表一2 のようそ選らび，次に $P(t)_{\max }=156695 \mathrm{~kg}$ を定值 持続載荷の場合（図一-3 (c)）の变形状態を検討した。

式（6）または (6)'のように運動方程式は 2 次の非線型微分方程式となるから，ここでは Runge-Kutta 法を 用いて数值積分を行う。このとき初期条件として次の值を用いる。すずトラスの固有振動周期は，現在考觉てい る強制力としての荷重の変化時間に比して十分小と考光られるから, 弾性変位量满重に比例するるのと考光て, $\delta_{d}$ : 死荷重のみによる点 $L_{4}$ (または $L_{6}$ ）の鉛直変位， $\delta_{l}$ ：活荷重のみによる点 $L_{4}$ （または $L_{6}$ ）の鉛直変位とす ると，

$\begin{array}{ll}\theta_{1} \fallingdotseq\left(\delta_{d}+\delta_{l}\right) /\left(L_{1}-L_{3}\right) \\ \text { 従つて } & \dot{\theta}_{1} \fallingdotseq \dot{\delta}_{l} /\left(L_{1}-L_{3}\right)=\delta_{l} /\left(L_{1}-L_{3}\right) t_{1}\end{array}$

$\delta_{d}$, 及び $P(t)_{\max }=156695 \mathrm{~kg}$ のときの $\delta_{l}$ を計算すると, $\delta_{d}=5.2989 \mathrm{~cm} ; \delta_{l}=17.2475 \mathrm{~cm}$ となる。従つて降伏 開始時の $\theta_{1}$ 及び $\dot{\theta}_{1}$ はとれぞれ

$$
\theta_{1, t=0}=8.0523 \times 10^{-3} ; \dot{\theta}_{1, t=0}=17.2475 / 2800 t_{1}
$$

また死荷重のみとよる回転変位を $\theta_{1 d}$ とすると， $\theta_{1 d}=5.2989 / 2800=0.001893$ である。

各場合の $\dot{\theta}_{1, t=0}$ の值は 表一2 の通りである。

一方荷重 No.6 受けると構造物の回転变位 $\theta_{1}$ の 増加に従つて部材 FG はヒズミ硬化を生じ始める。こ のときの回転変位 $\theta_{1 s}$ を求めると, 式 $(8)^{\prime},(10)$ より

$$
\begin{aligned}
\theta_{1 s}=\theta_{1, t=0}+\frac{\Delta l_{p}}{2 h} & =0.008052+0.022500 \\
& =0.030552
\end{aligned}
$$

となる。

e. 計算結果及びその考察 5.a の諸量を 用いてトラス運動方程式 (6)' 式を書けぼ次 の通りである。

$$
\begin{aligned}
\ddot{\theta}_{1}= & \frac{1}{206.9007+754.2854 \theta_{1}} \\
& \left\{\left(-377.1427+1000 \theta_{1}\right) \dot{\theta}_{1}{ }^{2}\right. \\
& +\left(-0.4574861+0.4752733^{\circ} \theta_{1}\right) \\
& +0.002955 P(t)\}
\end{aligned}
$$

“をたヒズミ硬化を生ずる領域に対しては，式 (11)'を用いて

$$
\begin{aligned}
\ddot{\theta}_{1}= & \frac{1}{206.9007+754.2854 \theta_{1}} \\
& \left\{\left(-377.1427+1000 \theta_{1}\right) \dot{\boldsymbol{\theta}}_{1}{ }^{2}\right. \\
& +\left(-0.4247351-0.9416572 \theta_{1}\right) \\
& +0.002955 P(t)\}
\end{aligned}
$$

となる。但し $P(t)$ は単位 ton

\begin{tabular}{|c|c|c|c|c|c|}
\hline $\begin{array}{l}\text { 荷重 } \\
\text { No. }\end{array}$ & $\left|\begin{array}{l}\text { 対応時速 } \\
(\mathrm{km} / \mathrm{hr})\end{array}\right|$ & $t_{1}(\mathrm{sec})$ & $\left|t_{2}(\mathrm{sec})\right|$ & $\theta_{1}, t=0(\mathrm{rad})$ & $\dot{\theta}_{1}, t=0(\mathrm{rad} / \mathrm{sec})$ \\
\hline 1 & 15 & 6.720 & 3.360 & $8.0523 \times 10^{-3}$ & $0.91664 \times 10^{-3}$ \\
\hline 2 & 25 & 4.032 & 2.016 & $"$ & 1.52774 \\
\hline 3 & 35 & 2.880 & 1.440 & $"$ & 2.13883 \\
\hline 4 & 45 & 2.240 & 1.120 & $"$ & 2.74993 \\
\hline 5 & 55 & 1.833 & 0.916 & $"$ & 3.36052 \\
\hline 6 & 55 & 1.833 & $\infty$ & $"$ & " \\
\hline
\end{tabular}

$P(t)$ として No. 1 No. 6 の各荷重をと り, 数值積分を行つた結果を図示すると, 図

\section{-4,5 及び 6 が得られる。}

図一4 核荷重 No. 1 4 亿対する変形の時 間的変化を示したもので, 下弦材降伏後の $\theta$

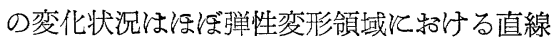
的変化を保つと見られるが, 荷重変化速度の 低い No. 1 あるいは No. 2 の場合は変形が 㴔激に增加しようとする傾向が顕著である。

\section{表一2}

\section{図一4 時間・構面回転量関係}

Fig. 4 Time-deformation relations under various loading

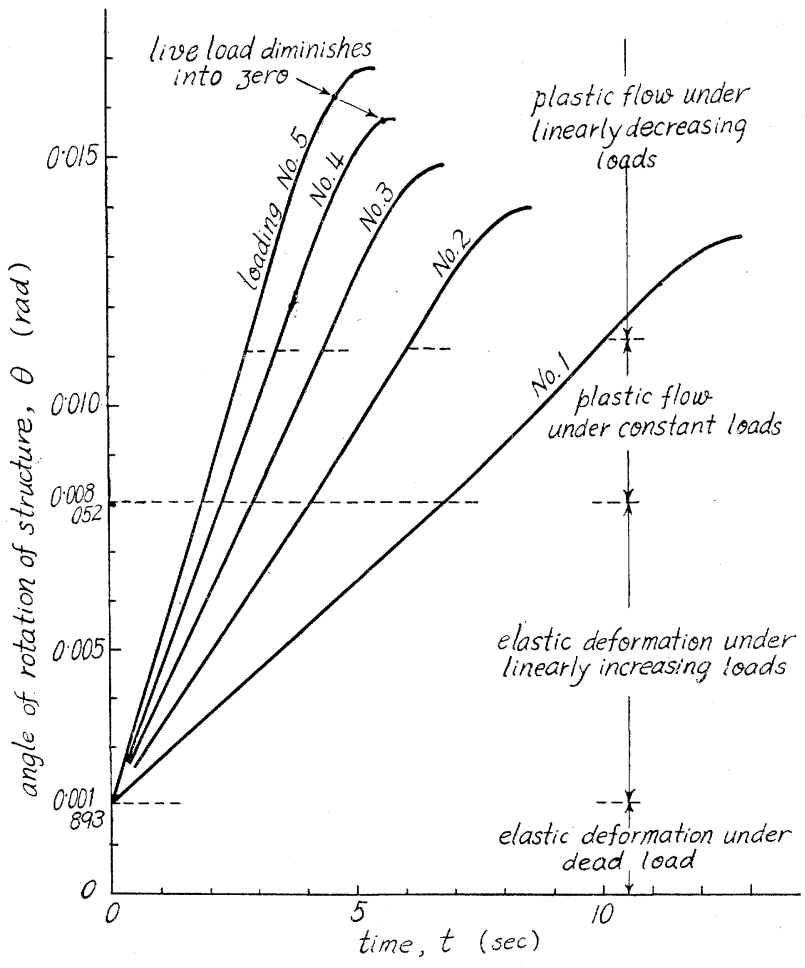


このことは図一5に示したトラス回転角速度 $\dot{\theta}$ の時間的変化状泻からも明らかで，いずれ の荷重によつても $\mathrm{a} \sim \mathrm{b}$ 間飞称いて白は増加 するが，荷重速度大の場合は $\mathrm{a}, \mathrm{b}$ が近接して

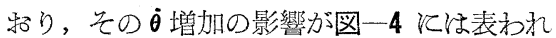
そくい。また荷重減少開始後はいずれの場合 も白は減少しはじめ, 荷重速度の低いNo. 1 ３の場合荷重が0となる以前飞変形の進 行核停止し, 荷重速度の高い場合满荷消滅 後間もなく停止するのが見られる(図一4)。 一方終局の変形量《荷重変化速度の增加飞伴 つてほぼ放物線的に増大するようである（表 $-3)$ 。

図一6 社荷重 No. 5 及び No. 6 江よる変 形の時間的変化を示したるのである。No. 6 のように最大荷重が持続される場合には，変 形は降伏部材のヒズミ硬化領域突入後も活と えぞそれ以前の変形増大速度を持続し， $\theta \fallingdotseq$ $0.1 \mathrm{rad}$ で変形が停止する。これは部材破壤 時の $\theta$ の大略 $1 / 2$ の值に相当する。

な特活荷重による弹性変形量飞等しい変形 回復が除荷後生ずるるのとして, 荷重 No. 1 ～5 亿よる残留変形量を算定すると表一3 が 得られる。表中のタワミ量 $\delta_{r}$ または $\delta_{\max }$ はいずれも格点 $L_{4}$ あるいは $L_{6}$ 汇ついての 值である。また $L$ はスパンを表わす。

\section{6. 結語}

台形状に増加・減少する 2 個の集中荷重を受ける静 定ピントラスの一下弦材降伏後の挙動を動力学的計算 によつて明らかにしてが，要点を挙げれば次の通りで める。

1）一下弦材降伏後のトラスの変形は，降伏部材を

\section{図一6 時間・構面回転量関係}

Fig. 6 Time-deformation relations under loading No. 5 and No. 6

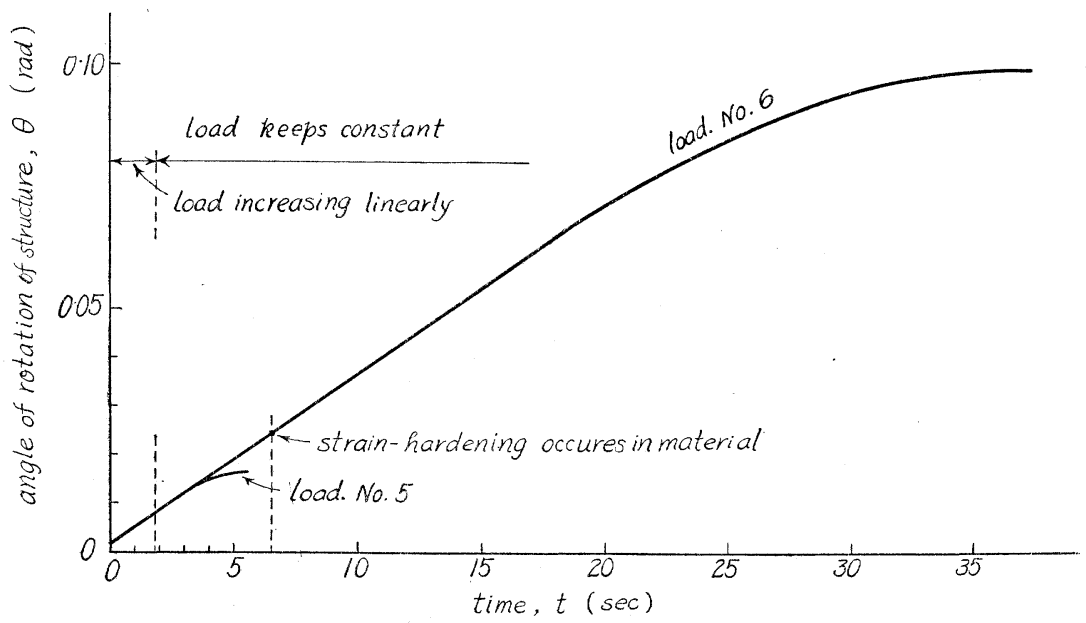


降伏部材力と等しい一対の定荷重で置き換え, それに相対するピンで結合された 2 つの構造部分よりなるメカニ ズムの運動方程式 (6) あるいは (6)' の解として与えられる。

2）降伏部材がヒズミ硬化開始後のトラスの変形を求めるとは，その部材伸びと，構面回転量との間の幾何学 的関係によつて降伏部材力を式 (11) あるいは (11)'で表わし，上記 1) の降伏部材力の代りに用いる。

次にスパン $70 \mathrm{~m}$ の下路ワレントラス道路橋についての数值計算結果より,

3）一下弦材降伏後の変形速度は，それ以前の弾性形変領域に比して急激になる傾向を有するが，それ荷重速 度の低い活ぞ顕著である（図一5）。この傾向も変形量について見ると荷重速度大の場合は顕著でない。

4) 荷重減少開始後は荷重速度の大小にかかわらず直ちと変形速度を減ずる。また荷重速度の低い場合 (35 $\mathrm{km} / \mathrm{hr}$ 以下の移動荷重による部材力変化飞相当）は荷重消減前飞変形の增加は停止する。

5）終局の変形量は荷重速度の増加に伴ない泳放物線的飞增大するようである。

6）最大タワミ，残留タワミは表一-3の通りである。

7）直線的に増大した荷重が最大值に達して後定値を持続する場合は 変形注著しく増大し，降代部材がヒズミ 硬化を生じて後も更江変形を増大し最後に変形を停止する。終局変形量は $55 \mathrm{~km} / \mathrm{hr}$ の移動荷重の相当荷重に対し て破壊時の大略 $1 / 2$ 程度飞達する。

以上は荷重及び材料に関する仮定を含んでほいるが，これとよつてピントラスの降代荷重による非弾性挙動の 概略を理解することができると思う。また設計荷重, 許容応力等の決定時に当然考虑されるべき構造物の極限状 態の一資料となれば幸と思う。

本研究を行うに当つては京大小西教授, 神大畑中教授より御指導御激励を仰ぎ, また昭和 30 年度文部省科学研 究助成補助金を受けた。ここと各位に深謝する次第です。

\section{参 考 交 献}

1) S.J. Fraenkel and L.E. Grinter: Nonelastic Behavior of Bridges under Impulsive Loads, Proc. ASCE, Vol. 79, Sep. No. 185, April 1953.

2) R. Lévi : Sécurité des constructions (The Safety of Structures), Prelim. Report, 2 nd Congr. Intern. Assoc. Bridge \& Structural Engg., W. Ernst \& Son, Berlin, 1936, p. 79.

(昭 31.11.27) 